\title{
Structure/Deformation Relationship in a $\beta$ Metastable Ti-Alloy
}

\author{
T. Grosdidier, C. Roubaud, M.-J. Philippe, S. Zaefferer*, M. Zandona**, E. Gautier** and \\ Y. Combres*** \\ Centre de Métallurgie Structurale, CNRS EP 0098, Université de Metz, Ile du Saulcy, 57045 Metz, France \\ * Institut für Metallkunde und Metallphysik, T.U., 38678 Clausthal, Germany \\ ** Laboratoire de Science et Génie des Matériaux Métalliques, URA 159 du CNRS, Ecole des Mines de \\ Nancy, 54042 Nancy, France \\ *** Centre de Recherche de CEZUS, BP. 33, 73400 Ugine, France
}

\begin{abstract}
This paper presents the first results of an ongoing research which was set up to investigate the influence of $\beta$-rich microstructures on the deformation mechanisms of the recently developed $\beta$-Cez alloy. Depending on the heat treatment, strong differences in the mecanical behaviour of this $\beta$ metastable alloy were obtained. They can be explained by the relative contribution of slip and formation of stress induced martensite during deformation. The relative contribution of the two mechanisms is influenced by the chemical composition of the $\beta$ phase and also by microstructural features. In particular, large $\beta$ grains are shown to favour the formation of stress induced martensite.
\end{abstract}

\section{INTRODUCTION}

In the $\alpha$ and $\alpha+\beta$ titanium alloys, a martensitic transformation of the high temperature $\beta$ phase can occur during quenching from above the $\beta$ transus. The martensitic structures observed in quenched titanium alloys are of two types : hexagonal closed packed $\alpha^{\prime}$ and orthorombic $\alpha^{\prime \prime}$ in alloys of high and low $M_{S}$ respectively. In the $\beta$ metastable alloys, the $M_{S}$ temperature is below room temperature and the $\beta$ phase can be retained in a metastable state. In many of the less stabilized $\beta$ alloys, the martensitic transformation can however be triggered by an external stress. The driving force for the transformation is now mechanical, as opposed to thermal. In that case, the temperature below which stress induced martensite (SIM) can form lies above room temperature and the temperature range for SIM to form is from $M_{s}$ to $M_{d}$. Stress induced transformation in $\beta$ titanium alloys has also been reported to result in the formation of $\alpha$ ' or $\alpha$ " martensites.

The deformation of $\beta$ titanium alloys can also involve slip or $\{332\}<113>$ twinning. $\{332\}<113>$ twinning mainly operates in binary alloys with large metastability of the $\beta$ phase and is almost always accompanied by the formation of stress induced $\omega$ phase. Crystallographic slip occurs in alloys with lower metastability of the $\beta$ phase and results in high yield strength and often small elongation. On the contrary, both $\{332\}$ twinning and deformation induced martensitic transformation cause lower yield strength and often higher elongation than slip does. Combinaison of slip with stress induced martensitic transformation [1] or combinaison of slip with twinning [2] have been reported to lead to a good compromise in terms of mechanical behaviour. It is therefore essential to identify the deformation mechanisms to understand and control the mechanical properties of the $\beta$ metastable alloys. The first goal of our research is therefore to investigate the deformation mechanisms of $\beta$ rich microstructures in the recently developped $\beta$-Cez alloy [3, 4] and see the extend to which they can explain differences in the mechanical behaviour.

Since the occurence of the different deformation modes depends strongly on the metastability of the $\boldsymbol{\beta}$ phase, the deformation mechanisms in $\boldsymbol{\beta}$ alloys have often been studied by varying the chemical composition of the master alloys or, for a given alloy, by including different volume fractions of $\alpha$ phase which in turn changes the chemical stability of the $\beta$ phase. For example, $\mathrm{Sn}$ and Al additions change the 
deformation mode from (332) twinning to deformation induced martensitic transformation in Ti-16V and $\mathrm{Ti}-7 \mathrm{Cr}$ whereas $\mathrm{Zr}$ addition has little influence $[1,5]$.

In the commercial Ti-10V-2Fe-3Al alloy, in which $\alpha "$ is induced under deformation when the alloy is fully $\beta$ metastable, heat treatment in the $\alpha+\beta$ domain allows the composition of the remaining $\beta$ phase to be rich enough in $\mathrm{Fe}$ and $\mathrm{V}$ to depress $\mathrm{M}_{\mathrm{d}}$ below room temperature : the material therefore deforms by slip and no $\alpha$ " is formed $[6,7]$.

If the influence of the chemical composition of the $\beta$ matrix on the occurence of the martensitic transformation has been demonstrated in $\beta$ metastable titanium alloys, the influence of microstructural parameters (such as the $\beta$ grain size or the distribution, shape and size of $\alpha p$ particles) has not been investigated yet. There is therefore a scope for research in this direction and the second goal of this research is to investigate the extend to which differences in the microstructure of a given $\beta$ metastable alloy with given volume fractions of primary $\alpha$ phase can influence the competition between the various deformation mechanisms. In turn, this will allow to adjust a microstructure design procedure with regard to required mechanical properties.

\section{EXPERIMENTAL PROCEDURE}

The $8 \mathrm{~mm}$ diameter wires used in this investigation were obtained by different steps of hot rolling. All samples studied in this work are from the same melt. The transus of this melt of $\beta$-Cez alloy was determined by differencial thermal analysis to be $878^{\circ} \mathrm{C}$. The chemical composition of the material was determined as (weight \%) :

$\begin{array}{llllllllll}\mathrm{Ti} & \mathrm{Al} & \mathrm{Sn} & \mathrm{Zr} & \mathrm{Mo} & \mathrm{Cr} & \mathrm{Fe} & \mathrm{O} & \mathrm{C} & \mathrm{N} \\ \text { base } & 4.89 & 1.99 & 4.36 & 3.99 & 2.00 & 0.93 & 986 & 56 & 54 \\ & & & & & & & (\mathrm{ppm}) & (\mathrm{ppm}) & (\mathrm{ppm})\end{array}$

Various heat treatments were given in the $\beta\left(920^{\circ} \mathrm{C}-0 \%\right.$ of $\alpha$ phase $)$ or $\alpha+\beta\left(850^{\circ} \mathrm{C}-\right.$ about $10 \%$ of $\alpha$ phase) fields in order to vary the different microstructural parameters. Heat treatments were stopped by water quenching.

The mechanical behaviour of the material was monitored by tensile testing on a Zwick machine at a rate of $1 \mathrm{~mm} / \mathrm{min}$. Tensile test samples were $3 \times 2 \mathrm{~mm}$ in section with a gage length of $25 \mathrm{~mm}$. Strains were measured using a clip-on extensometer. The mechanical behaviour data given in this paper are the average value of two or three tensile experiments. Some samples were also wire-rolled to obtain material that has undergone higher deformation levels.

Prior and after deformation, microstructures were examined and characterised using light and scanning electron microscopies. Deformation mechanisms were identified by transmission electron microscopy and X-ray diffractometry. Thin foils for TEM were prepared in a twin jet electropolishing unit, using a $5 \%$ perchloric acid $+30 \%$ butyl $+65 \%$ methanol solution, and observed in a $100 \mathrm{kV}$ Jeol microscope or a $300 \mathrm{kV}$ Philips microscope which was fully equiped for on line determination of dislocation characteristics and individual orientation measurements following a procedure described elsewhere [8]. Investigation of the tensiled samples by X-ray was done along their gage in an Inel - CPS 120 equipment operating with the $\mathrm{Fe} \mathrm{K} \alpha$ radiation and for declination angle varing from 0 to $60^{\circ}$ to avoid texture effects. Experiments on the wire-rolled samples were done on transverse, longitudinal and median ( $45^{\circ}$ from longitudinal and transverse) sections in a Siemens - D500 equipment operating with the Co Ko radiation. 


\section{RESULTS}

\subsection{Microstructure prior to deformation}

The following set of heat treatments was given :

- ( $\beta$ )ST15 : Solution Treated at $920^{\circ} \mathrm{C}$ for $15 \mathrm{~min}$. - Water Quenched

- ( $\beta$ )ST60 : Solution Treated at $920^{\circ} \mathrm{C}$ for $60 \mathrm{~min}$. - Water Quenched

$-(\beta)+(\alpha+\beta)$ ST $60: 920^{\circ} \mathrm{C}$ for $60 \mathrm{~min}$. - W.Q. - Solution Treated at $850^{\circ} \mathrm{C}$ for $60 \mathrm{~min}$ - W.Q.

$-(\alpha+\beta)$ ST15 : Solution Treated at $850^{\circ} \mathrm{C}$ for $15 \mathrm{~min}$. - Water Quenched

$-(\alpha+\beta)$ ST60 : Solution Treated at $850^{\circ} \mathrm{C}$ for $60 \mathrm{~min}$. - Water Quenched

The volume fraction of primary $\alpha$ phase was $0 \%$ in the ( $\beta$ )ST conditions and about $10 \%$ in the $(\alpha+\beta)$ ST conditions. By TEM, all conditions were also found to containt a little amount of athermal $\omega$ and were verified to contain no martensite resulting from the quench. The intensity of the $\omega$ spots in the diffraction patterns indicates that the volume fraction of $\omega$ phase is higher in the $(\beta) S T$ than in the $(\alpha+\beta) S T$ conditions.

Specimens treated above the $\beta$ transus were made of large beta grains the size of which was about 130 and $220 \mu \mathrm{m}$ for $(\beta)$ ST15 and ( $\beta$ )ST60 respectively. This is in relatively good agreement with the evolution of the $\beta$ grain size with time in the $\beta$ field given in the litterature $[9,10]$.

Sample $(\beta)+(\alpha+\beta)$ ST60 was given the same heat treatment as $(\beta)$ ST60 and was subsequently held at $850^{\circ} \mathrm{C}$ for $60 \mathrm{~min}$. and water quenched. As shown in figure 1 , the resulting microstructure was made of large $220 \mu \mathrm{m}$ grains in which high aspect ratio primary $\alpha$ particules had precipitated. The precipitation affected mainly the interior of the grains and the grain boundaries : a precipitate free area was observed along the grain boundaries. This microstructure is the result of precipitation of the $\alpha$ phase from a mixture of metastable $\beta+$ anisothermal $\omega$ phases [11].

Specimens directly solution treated below the $\beta$-transus contained small $\beta$ grains and globular primary $\alpha$ at the grain boundaries (figure 2). Because of the impingment of the $\beta$ grains by the primary $\alpha$ particules during the solution treatment, the $\beta$ grain size did not vary between the $(\alpha+\beta)$ ST 15 and $(\alpha+\beta)$ ST 60 conditions. The average $\beta$ grain size was about $10 \mu \mathrm{m}$ in both cases. Little coarsening of the primary $\alpha$ precipitates has occured : the average precipitate area and density varied from about $2.6 \mu \mathrm{m}^{2}$ and $3.1 \alpha_{\mathrm{p}}$ $/ 100 \mu \mathrm{m}^{2}$ respectively for $(\alpha+\beta) \mathrm{ST} 15$, to $3.5 \mu \mathrm{m}^{2}$ and $2.5 \alpha_{\mathrm{p}} / 100 \mu \mathrm{m}^{2}$ for $(\alpha+\beta) \mathrm{ST} 60$.

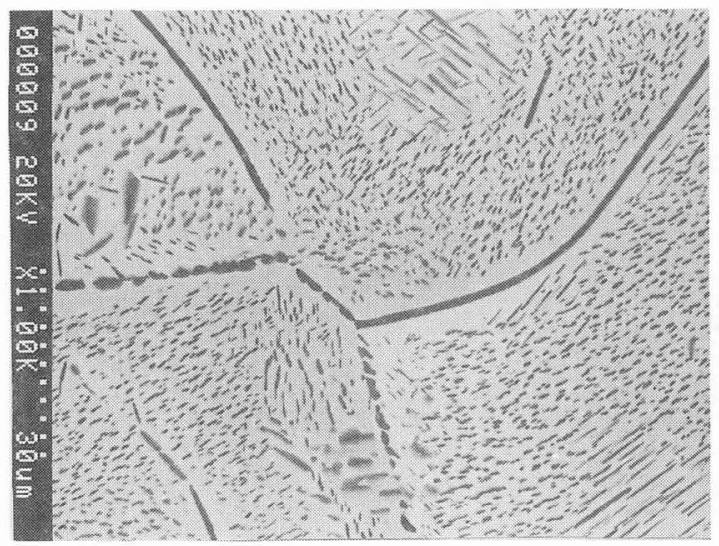

Figure 1 : SEM micrograph of the $(\beta)+(\alpha+\beta)$ ST60 condition.

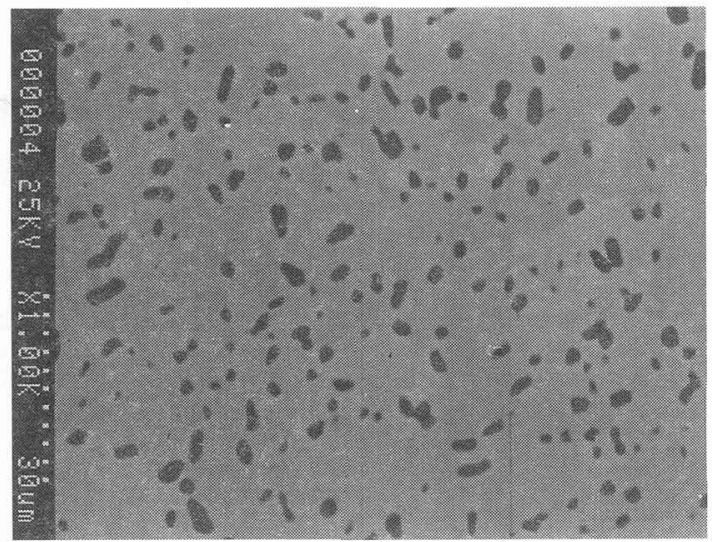

Figure 2 : SEM micrograph of the $(\alpha+\beta)$ ST60 condition. 


\subsection{Tensile testing and resulting microstructures}

\subsection{1. ( $\beta) S T$ treated samples}

Figure 3 illustrates the differences obtained in the stress/strain curves for the ( $\beta$ )ST15 and ( $\beta$ )ST60 samples. While the Ultimate Tensile Stress (UTS) values are almost identical (about 1020MPa), the apparent Yield Stresses (YS) are quite different : about 790 and $690 \mathrm{MPa}$ for ( $\beta$ )ST15 and ( $\beta$ )ST60 respectively. In the (ß)ST60 condition the stress/strain curve always showed a "double yielding" phenomenon.

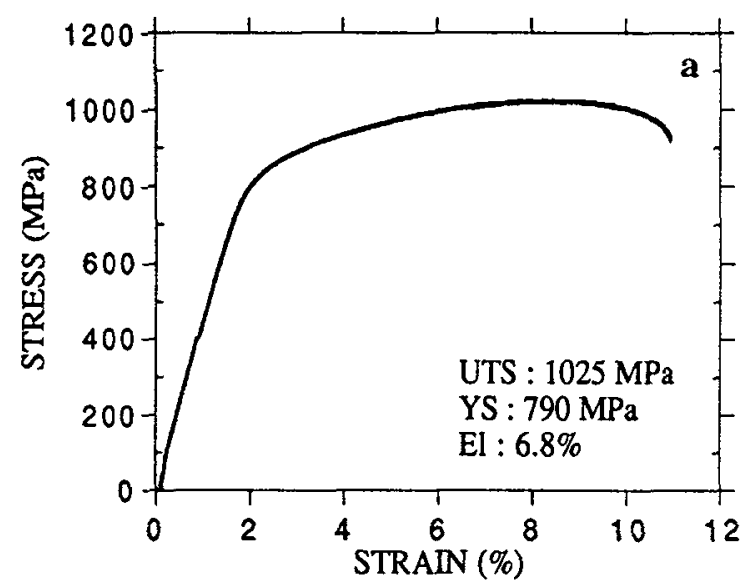

Figure 3 : Stress/strain curves and mechanical behaviour data.

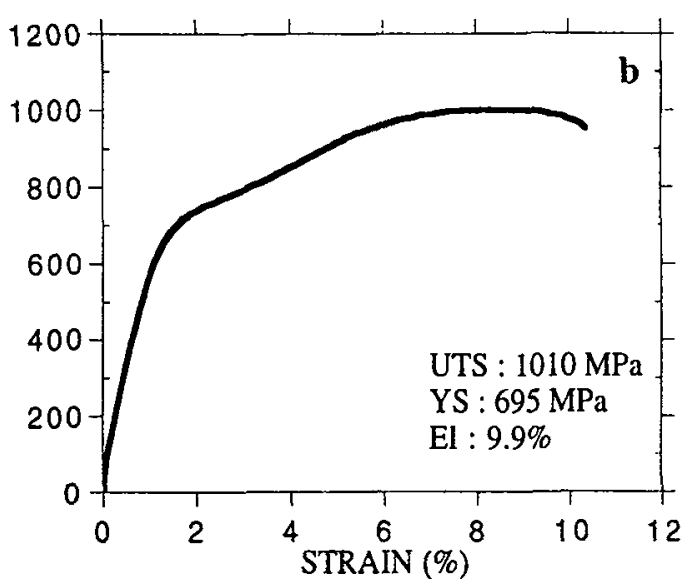

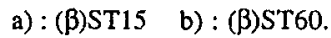

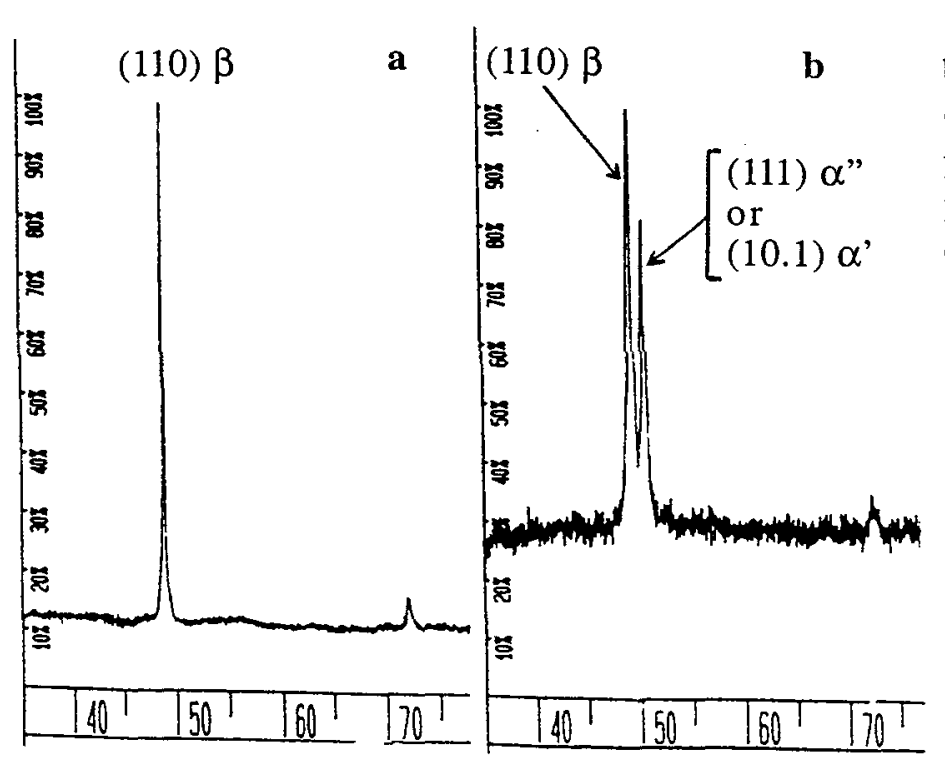

$\mathrm{X}$-ray diffraction was carried out before and after the tensile tests in order to detect any possible precipitation of stress induced phase. For both heat treatment conditions the diffraction profiles were similar. An example of profile is given in figure 4 for a ( $\beta$ )ST15 sample. Before deformation only peaks related to the $\beta$ phase could be detected. After deformation an additional sharp peak appeared on the side of the (110) $\beta$ peak. This peak does not correspond to the $\omega$ phase and can only be related to either the (10-11) hexagonal $\alpha^{\prime}$ or the (111) orthorombic $\alpha$ " peaks.

Figure $4: X$-ray diffraction for the $(\beta) S T 15$ condition a): before deformation b) : after deformation. 


\subsection{2. $(\alpha+\beta)$ ST treated samples}

Figure 5 shows examples of the stress/strain curves for the $(\alpha+\beta) \mathrm{ST}$ treated samples. Here again, several samples of each condition were tensile tested and all shown fairly similar behaviour. The X-ray diffraction profiles in figure 6 show some examples of the crystallographic changes produced by the room temperature deformation in these cases. X-ray of the $(\alpha+\beta)$ ST15 sample indicates that stress induced martensite has formed during deformation. Although, TEM has revealed the presence of some stress induced martensite in the $(\alpha+\beta)$ ST60, X-ray did not detect it. The volume fraction of SIM is therefore lower in $(\alpha+\beta)$ ST60 than in $(\alpha+\beta)$ ST 15. For these samples directly solution treated in the $(\alpha+\beta)$ field the average elongation to rupture were fairly similar. However, the yield stress is lowered in the $(\alpha+\beta)$ ST15 condition whereas the ultimate tensile stress reaches a higher value. This is believed to be associated with earlier formation of SIM in a larger amount.

Sample $(\beta)+(\alpha+\beta)$ ST60 showed a stress/strain curve characterised by very little work hardening. X-ray and TEM did not reveal SIM. In some grains, TEM showed slip bands in the $\beta$ phase associated with an intensive shearing of the primary $\alpha$ precipitates (figure 7). The dislocations on the gliding planes of the $\beta$ phase were of screw type with $<111>$ type burgers vectors, the gliding plane being (011). The deformation was fairly heterogeneous and such intense shearing was not observed in every grain. Indiviual orientation measurements carried out on a thin foil in the TEM have shown that the level of deformation in the grains was

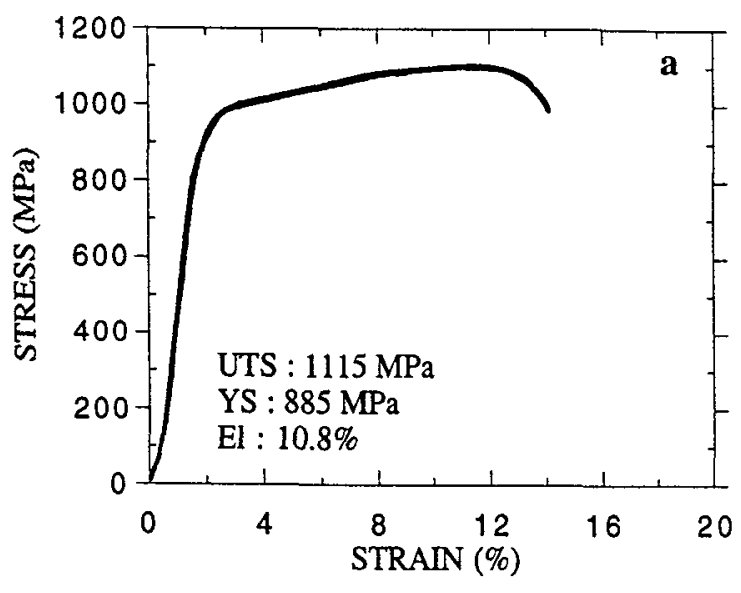
dependant on their orientation.
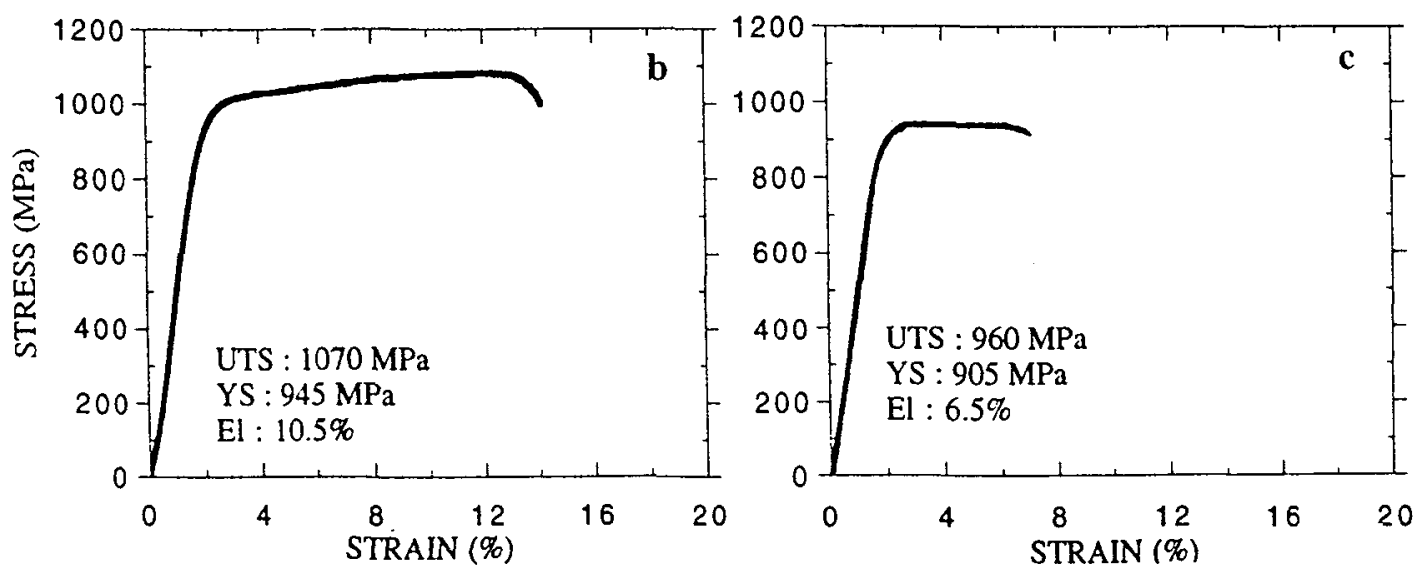

Figure $5:$ Stress/strain curves for the $(\alpha+\beta)$ ST treated samples : a) : $(\alpha+\beta)$ ST15, b): $(\alpha+\beta)$ ST60, c):( $\beta)+(\alpha+\beta)$ ST60. 


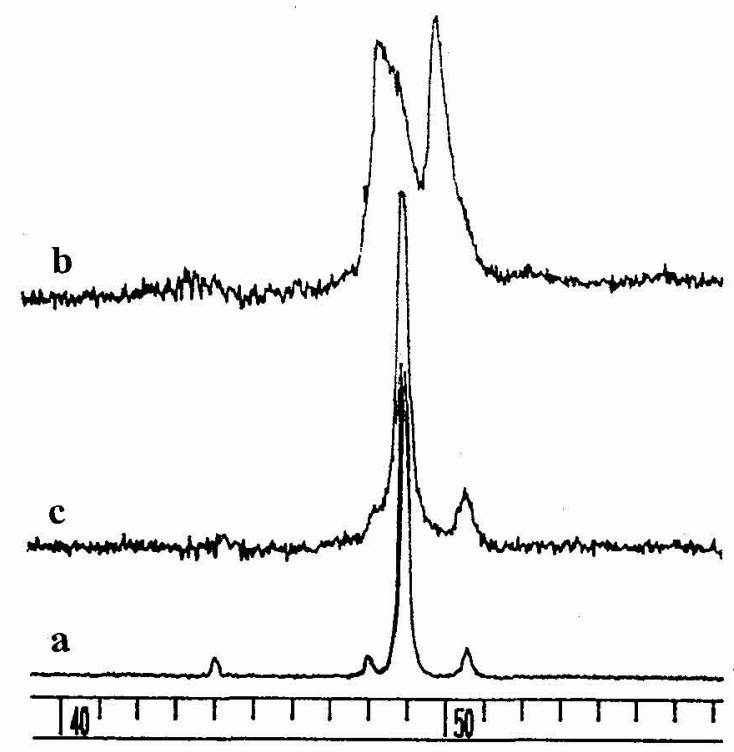

Figure $6: X$-ray diffraction for the $(\alpha+\beta) S T$ condition before (a) and after deformation : (b) : $(\alpha+\beta)$ ST 15, (c) : $(\beta)+(\alpha+\beta)$ ST 60

\subsection{Wire rolling}

In order to further investigate the nature of the SIM that forms in this alloy, samples chosen from the three conditions that have allow SIM under tensile test were deformed by wire rolling. Wires from the $(\alpha+\beta)$ ST 15 and $(\beta)$ ST15 were rolled until their edges start to crack but $(\beta)$ ST60 was given higher deformation. The $\mathrm{X}$-ray diffraction profiles before and after deformation are shown in figures 8 to 10 .

In the wire rolled $(\alpha+\beta)$ ST15 sample (figure 8 ), two additional peaks that correspond to $(020) \alpha "$ and $(021) \alpha "$ are observed after deformation. The intensity of the $(110) \beta$ peak is dramatically reduced.
Figure 7 : TEM micrograph showing shearing of primary $\alpha$ precipitates in a tensile tested $(\beta)+(\alpha+\beta)$ ST60 sample.
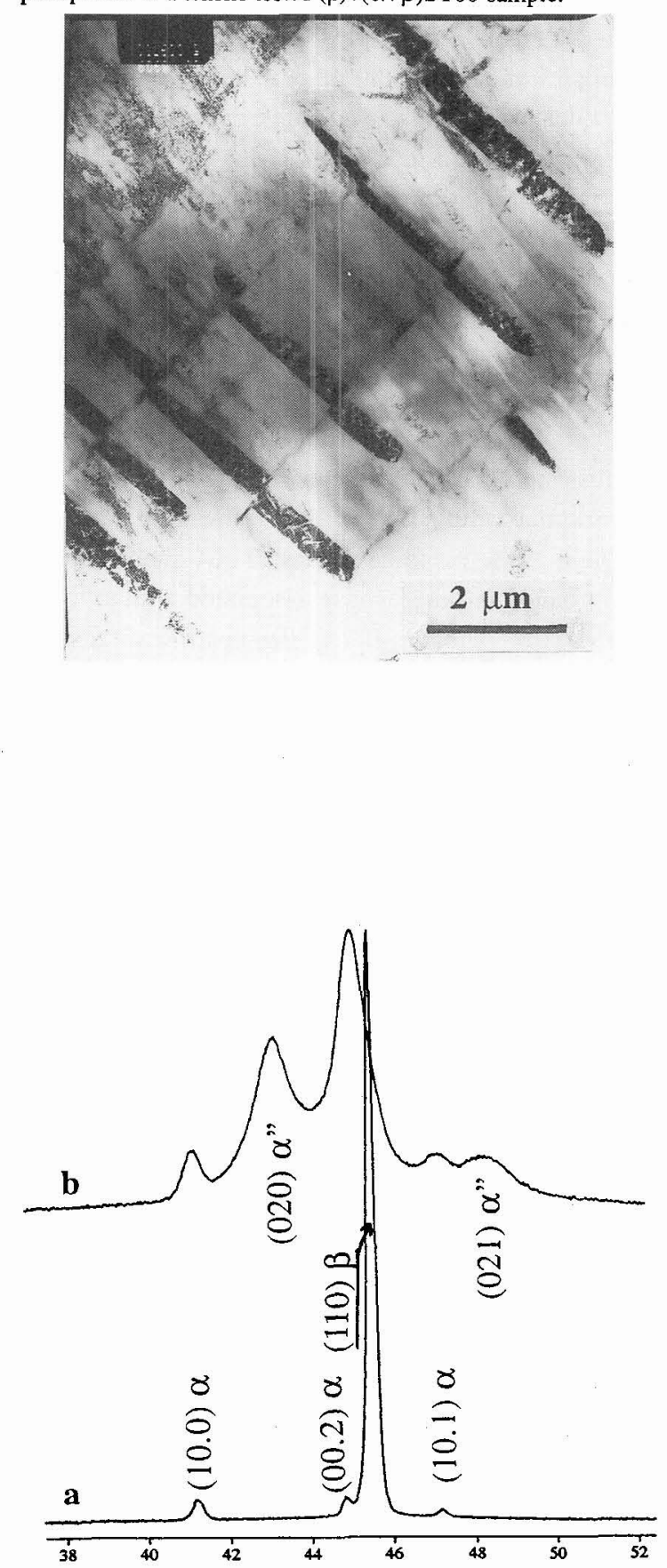

Figure 8 : X-ray diffraction for the $(\alpha+\beta)$ ST15 wire rolled until edge cracking.

a) : before deformation

b) : after deformation in transverse section. 
In the wire rolled ( $\beta$ )ST15 (figure 9), investigation in the transverse direction shows (020) $\alpha$ ", $(002) \alpha ",(021) \alpha "$ peaks and a tiny $(110) \beta$ peak. Along the longitudinal section the (111) $\alpha$ " shows up and the (020) $\alpha$ " and $(021) \alpha "$ are not observed. This shows the large texture effect that is associated with precipitation of stress induced martensite in these samples. Investigation along a median cut allows to see the five $\alpha$ " peaks.

In the heavily deformed ( $\beta$ )ST60 treated sample (figure 10) there is also a very strong texture effect. Compared to the $\alpha$ " phase observed in the samples rolled until edge cracking, the location of the peaks is shifted toward the hexagonal structure. It seems also that the $\beta$ phase has been further consumed than in the $(\beta)$ ST15 sample.

a) : before deformation b) : after deformation in transverse section c) : after deformation in longitudinal section d) : after deformation in medium section.

(Nota : the broard peak on the left hand side of the diffraction profile in longitudinal section of figure 10 is due to the holder)

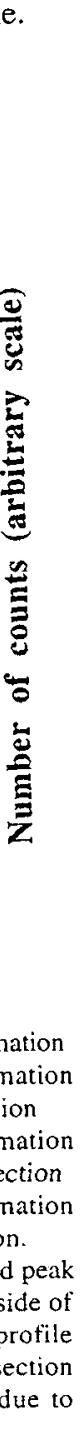

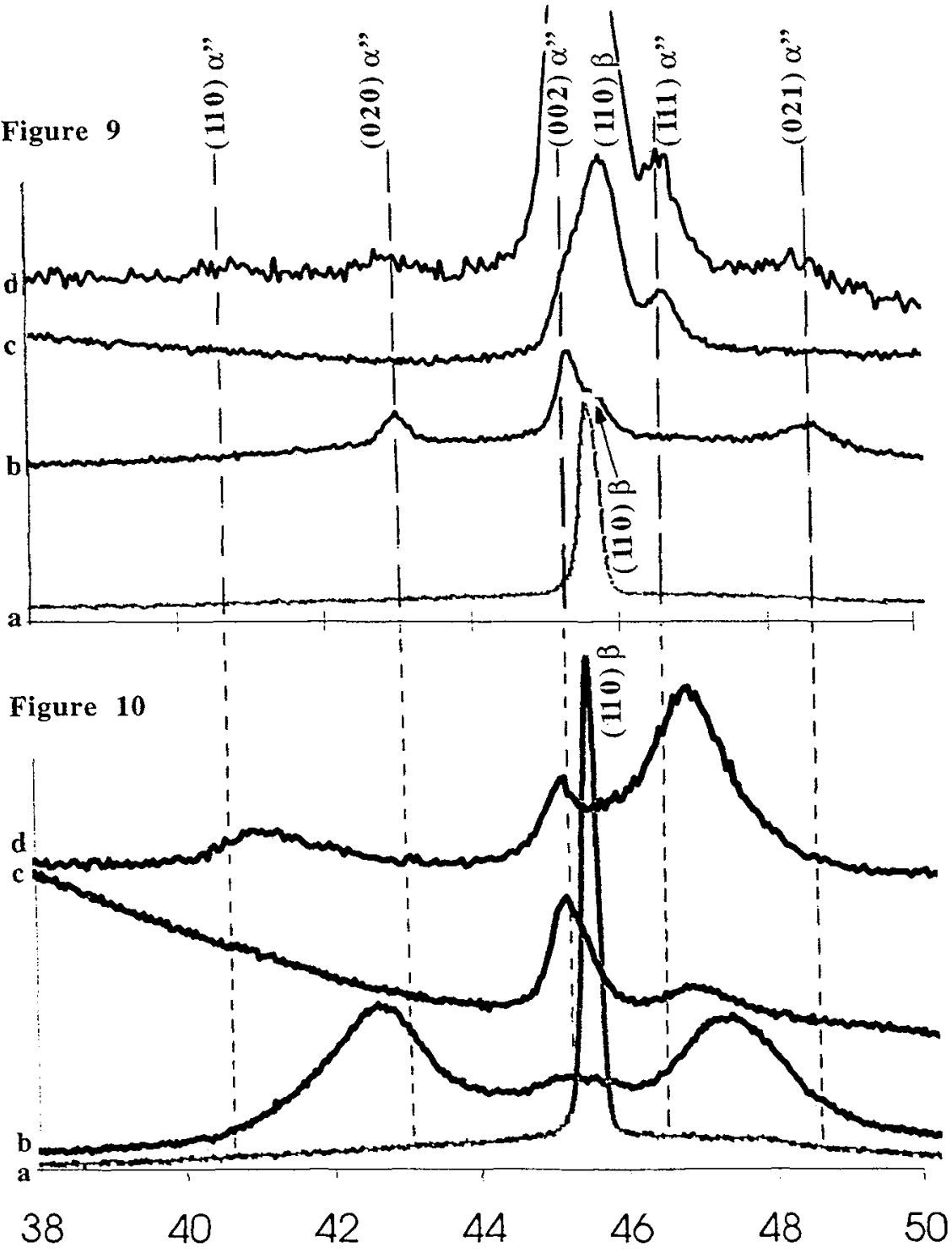

Figure 9 : X-ray diffraction for the $(\beta)$ ST15 wire rolled until edge cracking.

Figure 10 : X-ray diffraction for the wire rolled ( $\beta$ )ST60 sample ("heavily deformed"). 


\section{DISCUSSION}

The experimental results of the previous section clearly show that the $\beta$ phase in the $\beta$-Cez alloy accommodate deformation by activation of slip and/or formation of SIM. It is also appearent that the relative contribution of these mechanisms is influenced by the microstructure and generates strong differences in the mechanical response of the alloy.

In the ( $\beta$ )ST condition, observation of SIM is in agreement with the earlier study by Henri [12]. However, in the study by Henri, the stress/strain curve of a sample solution treated at $950^{\circ} \mathrm{C}$ ( $\beta$ domain) for $60 \mathrm{mn}$ did not show a double yielding effect. The mechanical behaviour was closer to what we observed in our ( $\beta$ )ST15 condition and the volume fraction of $\alpha$ " phase was considered to be relatively low. In our case, stress induced martensite was easily detected by X-ray diffraction for both the ( $\beta$ )ST15 and the $(\beta)$ ST60 conditions. The SIM has a significant influence on the mechanical response of the alloy : the stress required to produce SIM was much lower for $(\beta)$ ST60 than for ( $\beta$ )ST15 and a double yielding effect was observed in the ( $\beta)$ ST 60 .

Difference in critical stress to induce martensite can be attributed to changes in the $T_{0}$ temperature or, for a given $\mathrm{T}_{\mathrm{o}}$ temperature, changes in the $\mathrm{M}_{\mathrm{S}}$ temperature. In the case of this study, the difference between the two ( $\beta$ )ST60 and ( $\beta$ )ST15 conditions can not be attributed to changes in the $\mathrm{T}_{\mathrm{o}}$ temperature since the samples are from the same melt and have undergone the same thermomecanical treatment before the solution treatment. Also, it is worth noting that the difference in the level of applied stress to induce martensite between ( $\beta$ )ST60 and ( $\beta$ )ST15 can not be ascribed to a non-complete homogeneisation of the $\beta$ phase in the ( $\beta$ )ST15 sample. Indeed, $\beta$ lean area due to chemical segregation would be more susceptible to easily form stress induced martensite. For a given $\mathrm{T}_{\mathrm{O}}$ temperature, the stress needed to produce SIM can also be varied by changing the temperature at which the tensile test $\left(T_{t}\right)$ is carried out between $M_{S}$ and $M_{d}$ : the higher the difference between $\mathrm{T}_{\mathrm{t}}$ and $\mathrm{M}_{\mathrm{s}}$, the greater the stress required to produce martensite. In our study, $T_{t}$ was the same for every test and the different levels of stresses required to induce martensite can only be explained by considering the influence of the microstructure on the nucleation of martensite and therefore on $\mathrm{M}_{\mathrm{S}}$.

During the nucleation and growth process of a martensite plate, the shape strain of the forming variant must be acommodated. Any factor which is able to hinder or favor this accommodation can therefore affect the transformation. Kajiwara [13] has described some interesting results that tend to clarify the role of grains and dislocations on the nucleation of athermal martensite in ferrous alloys for which the $M_{S}$ temperature is below room temperature. Decreasing the grain size of the parent phase lowers the $M_{S}$ temperature. The main factor for depressing $M_{S}$ is the increased yield strengh of austenite by grain refining. This relationship can be understood in terms of the fact that decreasing the grain size makes it more difficult to accomodate the shape change of a martensite plate in a parent grain. Therefore, a greater driving force, available at lower temperature, is require for nucleation of athermal martensite. Considering SIM, a change in $\mathrm{M}_{\mathrm{s}}$ temperature will induce a change in the critical stress for a given $\mathrm{T}_{\mathrm{t}}$. When grain is refined, $\mathrm{Ms}$ is decreased and a greater driving force, available at higher level of applied tensile stress, is required for nucleation of SIM. This finding of the influence of the grain size on the formation of stress induced martensite shows some similarities with the influence of the grain size on the activation of twinning in $\beta$ titanium alloys [14]. Also, relationship between the critical stress of transformation, $M s$ and grain size was recently observed in a CuAlBe shape memory alloy [15].

In the case of the experiments by Henri, the solution treatment was carried out at $950^{\circ} \mathrm{C}$ for $60 \mathrm{mn}$ [12] and the $\beta$ grain size is therefore likely to be even larger than ours. The difference between the two studies could be attributed to different chemical composition of the master alloy leading to different 
equilibrium $\mathrm{T}_{\mathrm{o}}$ temperature. Measurement of $\mathrm{Ms}$ in various condition should provide more information to confirm our assumption.

In the $(\beta)+(\alpha+\beta)$ ST 60 and $(\alpha+\beta)$ ST60 conditions the formation of SIM is less favoured because the $\beta$ phase is more stable than in the $\beta$ quenched condition. The reason for this are two folds. Firstly, in the $(\alpha+\beta)$ domain, the chemical composition of the $\beta$ phase is enriched in $\beta$ stabilising elements and depleted in $\alpha$ stabilising elements because of the presence of primary $\alpha$ precipitates [10]. Therefore the $T_{0}$ temperature is lowered and formation of SIM is more difficult. Secondly, because of the $\beta$ grain refining $((\alpha+\beta)$ ST60) and/or the precipitation of primary $\alpha$ phase within the large high temperature $\beta$ grains $((\beta)+(\alpha+\beta)$ ST60)), the $\beta$ domain that are succeptible to transform are much smaller than in the $\beta$ solution treated samples. As pointed out earlier in the discussion, this makes it more difficult the accommodation of the martensitic shape strain and $\mathrm{M}_{\mathrm{S}}$ is lowered.

Although the grain size is also reduced in the $(\alpha+\beta)$ ST15 condition, SIM is likely to have formed because of the metastability of the $\beta$ phase associated with a non equilibrium chemical composition after a dwell time of $15 \mathrm{~min}$ only at $850^{\circ} \mathrm{C}$. This leads to a lower value of apparent yield stress.

Under tensile condition, the formation of SIM (often in combination with slip) allows improved elongation to rupture and better work hardening response. The poor level of work hardening when slip is activated solely in the $(\beta)+(\alpha+\beta)$ ST 60 condition, is explained by the fact that the primary $\alpha$ precipitates are easily sheared. As shown by the comparison of the $(\beta)$ ST60 treated samples with the $(\beta)+(\alpha+\beta)$ ST 60 , where the average high temperature $\beta$ grain size is the same, the precipitation of the primary $\alpha$ precipitates allows only an increase in yield strength. Once the $\alpha$ p precipitates are sheared, the work hardening effect relies on the matrix only. The fact that deformation is fairly heterogeneous when slip is activated solely is believed to have a detrimental effect on the elongation to rupture. On the contrary, the early formation of SIM in the ( $\beta$ ST60, to which is associated a certain amount of strain, is more likely to prevent early necking.

Another interesting feature concerning the SIM in this alloy is that X-ray diffraction analysis carried out on the wire rolled samples deformed until edge cracking showed peaks corresponding to the orthorombic $\alpha$ " phase, whereas, in the heavily deformed condition peaks were closer to the hexagonal $\alpha$ ' phase. Nwobu and coworkers $[16,17]$ have shown that a strain induced $\alpha " \rightarrow \alpha$ ' transformation takes place in the T134, T129 and Ti-10V-2Fe-3Al alloys. They have also shown that the strain induced transformation does not involve the nucleation of $\alpha$ ' plates in the $\alpha$ " phase and that this transformation is of secondary type. Similar behaviour could occur in the $\beta-\mathrm{Cez}$ alloy leading to a change in the $\mathrm{a}_{\alpha}$ " $/ \sqrt{3} \mathrm{~b}_{\alpha \text { " ratio }}$ toward unity. After its formation, the $\alpha$ " martensite in the heavily deformed sample has undergone higher deformation and the strain induced $\alpha " \rightarrow \alpha$ ' transformation is therefore more advanced than in the other samples.

\section{CONCLUSION}

The study of the deformation of the $\beta$-Cez alloy in its $\beta$-rich domain has shown some interesting features that can be summarized as follows :

(i) The microstructure accommodate the deformation by activation of slip and/or formation of SIM. The SIM is first an orthorombic $\alpha$ " phase. With increasing deformation the transformation follows the strain induced $\beta->\alpha$ " $\rightarrow \alpha$ ' sequence.

(ii) The occurence of the two mechanisms is influenced by the composition of the $\beta$ phase and also by microstructural features such as the size of the $\beta$ domains. In particular, large $\beta$ grains favour the formation of stress induced martensite. 
(iii) The relative contribution of the two mechanisms generates strong differences in the mecanical behaviour of the alloy. Formation of SIM leads to lower values of apparent yield stress. Under tensile condition, the formation of SIM in combination with slip often allows improved elongation to rupture and better work hardening response in the $\beta-\mathrm{Cez}$ alloy. Poor level of work hardening are obtained when slip is activated solely.

\section{Acknowledgments}

The authors wish to thank Professor R.A. Schwarzer for the provision of TEM facilities at the Institut für Metallkunde und Metallphysik-Clausthal and Professor J. Heizmann for the provision of some X-ray facilities at the Centre de Métallurgie Structurale-Metz. They also whish to thank Dr. J.J. Fundenberger and C. Laruelle (CMS) for helping with the X-ray investigations and P. Clerc (CEZUS) for carring out heat treatments on the samples.

\section{References}

[1] Ishiyama S. and Hanada S., The Sumitomo Search, 54, (1993), 41-47

[2] Nicotra A. and Philippe M.J., "Strain mechanisms and mechanical properties of various $\beta$-Ti alloys", Beta Titaniun Alloys, A. Vassel, D. Eylon and Y. Combres Eds (La revue de métallurgie, 1994), 189-196

[3] Prandi B., Alheritiere E., Schwartz F. and Thomas M., “ $\beta$-Cez, a high performance Titanium alloy for aerospace engines", Sixth word conference on titanium, , Part II, P. Lacombe, R. Tricot and G. Béranger Eds (Les editions de physique, Les Ulis, 1988), 811-818

[4] Combres Y. and Champin B. et al., Matériaux et Techniques, May-June (1991), 31-41

[5] Ishiyama S., Hanada S.and Izumi O., , ISIJ International, 31, (1991), 807-813

[6] Duerig T.W., Terlinde G.T., Williams J.C., "Stress assisted transformation in Ti-10V-2Fe-3Al", Forth wòrld conference on titanium, Kimura and Izumi Eds, (TMS AIME Warrendale, 1980), 1503-1512.

[7] Duerig T.W., Middleton R.M., Terlinde G.T., Williams J.C., Met. Trans. A, 11, (1980), 1987-1998

[8] Zaefferer S. and Schwarzer R.A., Mat. Sci. Forum, 157-162, (1994), 241-246

[9] Combres Y. and Champin B., "Processing, properties and application of the $\beta$-Cez alloy", $\beta$-Ti alloys in the 90's, Eylon et al. Eds, TMS, (1993), 27-38

[10] Béchet J., Angelier C., Cormier B., Lacagne O. and Lhermitte M. "Phase transformation in a near $\beta$ Ti alloy : microstructure and mechanical properties", Seventh world conference on titanium, Part III, Froes F.H. and CAPLAN I.L. Eds (TMS, 1992), 643-650

[11] Sanguinetti R. and Gautier E., "Alpha phase morphology and associated phase transformation sequences during thermal treatments of beta and alpha/beta titanium alloys", Beta Titaniun Alloys, A. Vassel, D. Eylon and Y. Combres Eds (Edition de la revue de métallurgie, 1994), 93-100.

[12] Henri A., PhD Thesis, Université de Paris VII, (1993)

[13] Kajiwara S., Met. Trans. A, 17, (1986), 1693-1702

[14] Laheurte P., CNAM-Thesis, Université de Metz, (1993)

[15] Barbe P. and Eberhardt A., Private communication, LPMM-Université de Metz, (1995)

[16] Nwobu A.I.P., Flower H.M.and West D.R.F., "Decomposition of stress-induced and deformed orthorombic $\alpha$ " martensite in near $\beta$-Ti alloys", Sixth word conference on titanium, , Part III, P. Lacombe, R. Tricot and G. Béranger Eds (Les editions de physique, Les Ulis, 1988), 1583-1588

[17] Nwobu A.I.P., Flower H.M.and West D.R.F., Journal de Physique, supplément au $N^{\circ} 12,43$, C4, (1982), 315-320 